\title{
Influence of mechanical disperator designer parameters on equality of distribution of solution
}

\author{
Andrii Lyubeka, Yaroslav Kornienko, Olesandr Martynyuk
}

\author{
National Technical University of Ukraine "Igor Sikorsky Kyiv Polytechnic Institute"
}

\begin{tabular}{l}
\hline Keywords: \\
Disperator \\
Distribution \\
Spraying \\
Fluidized bed \\
Dehydration \\
\hline
\end{tabular}

\section{Article history:}

Received 17.12.2017

Received in revised form

25.01.2018

Accepted 29.03.2018

\section{Corresponding author:}

Andrii Lyubeka

E-mail:

andrelyubeka@gmail.com

DOI: $10.24263 / 2304-$

974X-2018-7-1-10

\section{Abstract}

Introduction. The results of experimental studies the influence design a mechanical disperator on the uniform distribution of a fluid in the volume of the working zone are presented.

Materials and methods. The experimental plant is equipped with volume circular circuits for measuring the flow of liquid phase over the working length of the disperator. As a model liquid, water is used at a temperature of $18{ }^{\circ} \mathrm{C}$. From the experiment, the average costs of the liquid phase and the mass fractions of their distribution along the length of the working zone are determined by removing the liquid from the cells of the ring module. The number of weak rotations of the dispersator was measured by an electron frequency in $\mathrm{Hz}$ with an accuracy of $\pm 1 \mathrm{~Hz}$. Determination of the size of droplets was carried out by means of photographic fixation.

Results and discussion. At application of mechanical Cone type disperator with $450 \mathrm{x}$ per cent centrifugal force over gravitational force on the outer surface of a mechanical disperator of conical shape due to the presence of surface tension forces, fluid jets are formed which move to the edge of the disperator and facilitate the local re-use of the irrigation working zone.

The use of a conical disperser with the installation of external roller rings has increased the uniformity of distribution. The proposed criterion of estimation of uniformity allows to make a comparison of any designs of mechanical disperators according to the original method. In addition, a rational way of installing the feed supply tube of the working solution has been determined. By the results of the study have been determined, the parameters at which the size of the volume of spraying is increased with sufficient uniformity with the use of a mechanical two-cone disperator with a perforated lateral surface and the presence of external deflecting rings.

Conclusions. The expediency application of the proposed criteria for assessing the quality of work of a mechanical disperator has been theoretically substantiated and experimentally proved, which allow to determine the conditions of qualitative conduction of watering and granulation of liquid systems in the fluidized bed. 


\section{Introduction}

The obtaining of solid composites with given properties during dehydration of liquid heterogeneous systems is the most appropriate use of pseudo-irradiation techniques $[1,2]$.

In particular, in the production of granulated humic-mineral fertilizers, the finished product has a spherical shape with a uniform distribution of nutrients, micronives and humic substances, the content of which does not exceed $2 \%$ in relation to dry substances [3].

The stable kinetics of the process efficiency is determined by the method of regulation of the device for introducing the liquid phase.

\section{Analysis of scientific works}

The authors [4] established the influence of the geometrical construction, the linear parameters of the working surface of the disperator and the rheological properties of the liquid phase on the size of droplets, when the number of revolutions increases, is transformed in the form of a film on the edge of the disperator. Such a mode of operation is unsuitable for the case of dehydration and granulation of liquid systems, as it leads to a local overflow and as a consequence of the formation agglomerates.

In works [4-5] various mechanisms of spray dispersion were investigated, using a highspeed chamber. In their experiments, two different glycerin/water mixtures and three different designs of disperators with external diameters of $0.090,0.11$ and $0.128 \mathrm{~m}$ were used. Three studies of the disintegration mechanism were observed. However, the problem of local overflow was not effective.

The influence of the mechanical disperator structures on the size of droplets was investigated in [6-7]. As a result, a comparative analysis of the distribution, depending on the size of the droplets obtained with the help of seven different design disks operating at a flow rate of 660 liters per hour, and a linear velocity of $63.5 \mathrm{~m} / \mathrm{s}$, showed that the design of the disk had a minor effect on the size distribution of drops. The investigated parameters in these experiments were the number of blades built into the rotating surface and their configuration. But such designs can not be used when placing a disperator in the middle of a layer of granular material, due to the high risk of crushing granules.

In works [8-9], rotary discs with different edge profiles such as acute edge, straight edge, tilt edge and round edge with different radius were considered. It is determined that the change of the edge profiles leads to insignificant differences in the size of the droplets and does not allow to form a liquid phase on the surface of the granule in the form of a thin film, which leads to agglomeration of the granule by the formation of "liquid bridges".

However, studies [10] concluded that clamping the edge of a cup or disk delayed the transition from the chain mode to the film mode and pok-raises the quality of spraying, but does not solve the problem above.

Previous studies have established [11] that the use of a disk disperser leads to local overflow at the expense of reducing the working area for the introduction of liquid specialty and the formation of agglomerates with subsequent impulse process. Therefore, in order to prevent these shortcomings, it is proposed to apply a new design of a mechanical disperator with increased zone dispersion. 


\section{Materials and methods}

\section{Experimental device}

The research was carried out on an experimental stand designed by the auto-frame which allows measuring the irrigation density of the working zone on the outer surface Figure 1.

The speed of the disperator was measured by an electronic frequency meter in the range of 50-90 1/s with an accuracy of \pm 0.5 . As a model liquid, water was used. The liquid phase was measured by a volumetric method with an accuracy of $\pm 0,111$.

\section{Materials}

At a given rotational frequency of the disperator and constant losses, the liquid supplied by the feed tube 6 , Figure 1 in time $\Delta \tau=60 \mathrm{~s}$ was distributed by a mechanical disperator in the annular chamber 5, in which, with an interval $\Delta \mathrm{l}=6 \mathrm{~mm}$, the ring partitions were installed. Each ring cell is connected to the measuring flasks 7 . The height of the liquid in the flasks allows you to determine the distribution histogram, the liquid phase.

\section{Measuring complex}

Constructions of 3 types of conical disperators with a perforated surface were investigated. Distance of the edge of the cell in the ring chamber 5, Figure 1, to the edge of the disperator is $\Delta \mathrm{Z}=15 \mathrm{~mm}$.

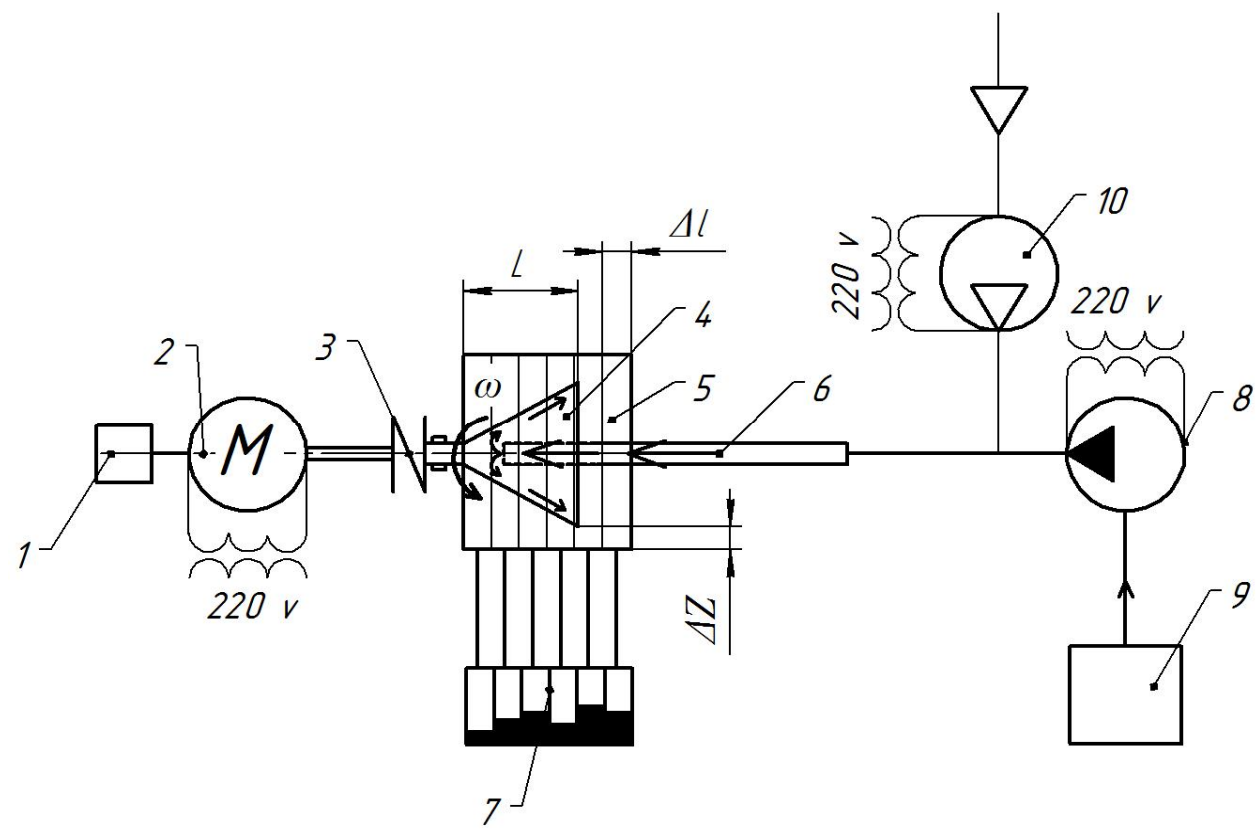

Figure 1. Test bench to evaluate the uniformity of dispersion:

1 - electronic frequency meter; 2 - engine; 3 - coupling; 4 -disperator; 5 - annular collection chamber; 6 - tube for delivery of a solution; 7 - measuring flasks; 8 - peristaltic pump; 9 capacity of a liquid; 10 - compressor. 


\section{Results and discussion}

Mechanical disperator type 1 , Figure $2 \mathrm{a}$, is a cut cone with a large diameter $\mathrm{D}=80$ $\mathrm{mm}$, smaller D1 $=40 \mathrm{~mm}$ and a width $\mathrm{L}=47 \mathrm{~mm}$. In the end-ears, the plane $\mathrm{G}$ has 4 holes diameter $4.5 \mathrm{~mm}$. The angle at the top of the cut cone $25^{\circ}$ prevents the formation of sediment on the working surface.

On the lateral surface of the disperator type 1, Figure 2a, in the spiral trajectory of the uniformly located apertures of $4.5 \mathrm{~mm}$ in diameter. Relative area to the side surface of the disperator, the coefficient of the living section

$$
\varphi=\frac{f_{\text {holes }}}{F_{\text {lateral }}} \cdot 100 \%=4 \%
$$

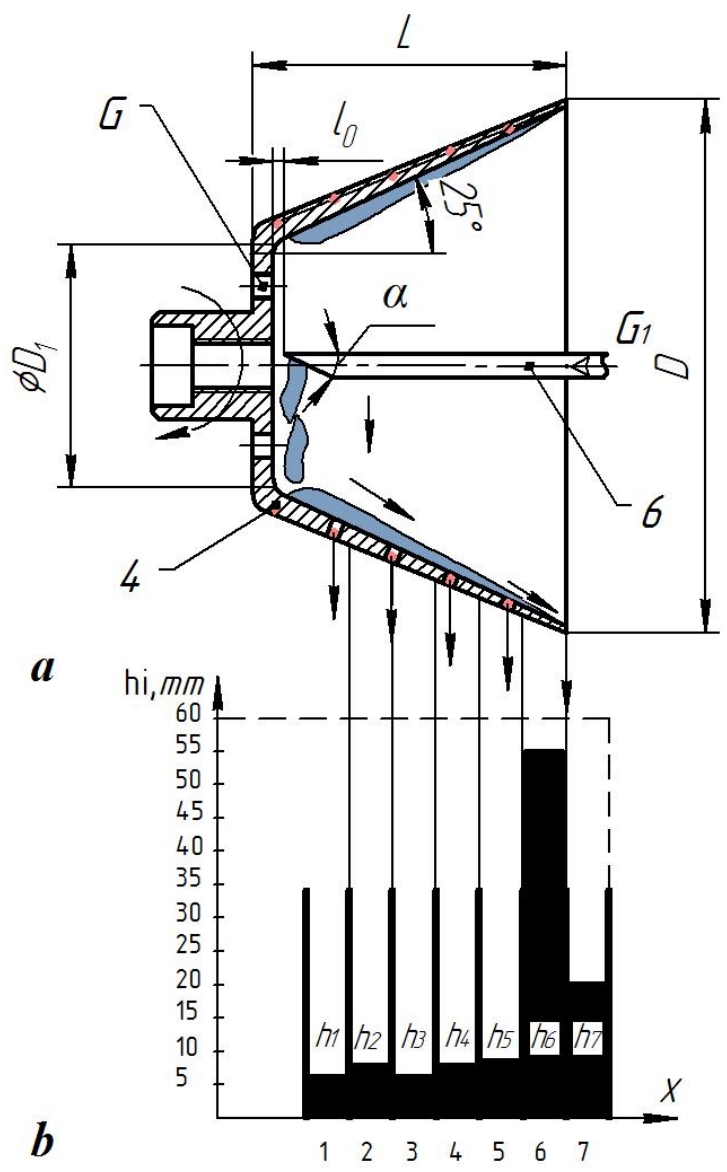

Figure 2. Mechanical disperator type 1:

4 - the disperser body; 6 - liquid supply line a-Type 1 disperator design;

$b$ - the histogram of the distribution of the liquid in the length $G=12,44 \mathrm{~kg} / \mathrm{h}$; $a=0,073 \mathrm{~kg} /(\mathrm{m} \cdot \mathrm{s}) ; \mathrm{n}=601 / \mathrm{s} ; \mathrm{w}=9 \mathrm{~m} / \mathrm{s} ; \mathrm{L}=0.47 \mathrm{~mm}$. 
The peculiarity of introducing the liquid phase lies in the fact that the feeding tube 6 , Figure 2a has a cut at an angle of $30^{\circ}$, which is turned down, and the end is at a $1_{0}=2 \mathrm{~mm}$ distance from the inner face of the disperator.

From previous studies [1] found that the linear velocity of the edge disperator with a diameter $\mathrm{D}=47 \mathrm{~mm}, w_{l}=9 \mathrm{~m} / \mathrm{s}$, which is achieved with a disperator wrapping frequency of $n=601 / s$.

For a comparative characterization of the mechanical disperator, a linear load is proposed for the mass flow rates of the liquid phase:

$$
a=\frac{G}{L \cdot 3600}
$$

where $\mathrm{G}$ - mass flow of liquid, $\mathrm{kg} / \mathrm{h}, a$ - length of disperator, $\mathrm{mm}$;

Experimentally, the distribution of the mass of the fluid, along the length of the working area, is expressed in terms of the ratio of heights (Figure 1):

$$
h_{1}: h_{2}: h_{3}: h_{4}: h_{5}: h_{6}: h_{7}=0.9: 1.1: 0.9: 1.1: 1,2: 11: 3
$$

in dimensional flasks 7. A tenfold excess of height $h_{6}$ is due to the fact that, due to the forces of surface tension on the outer surface of the disperator, streams of rice are formed, Figure $3 \mathrm{a}, \mathrm{b}$.

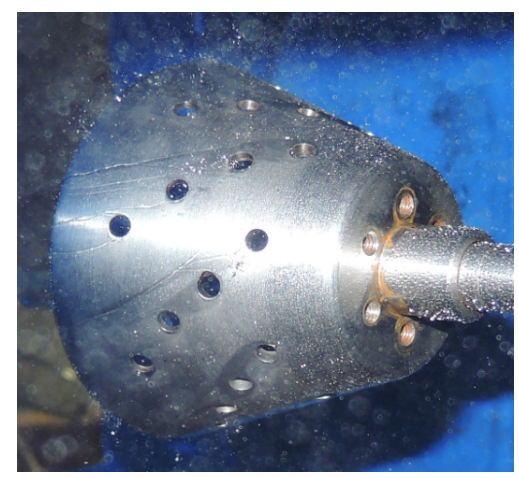

$a$

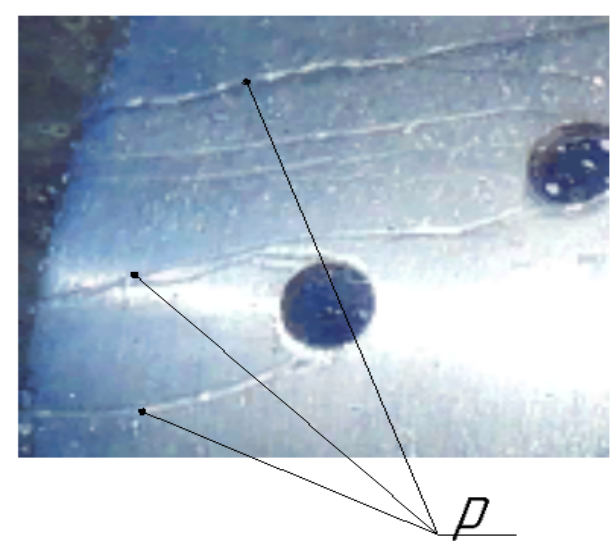

$\boldsymbol{b}$

Figure 3. Nature of movement on the outer surface of the disperator type 1: a - General view of outer surface; b - Liquid flow by outer surface.

To eliminate this phenomenon, designed the disperator type 2, Figure 4a. 


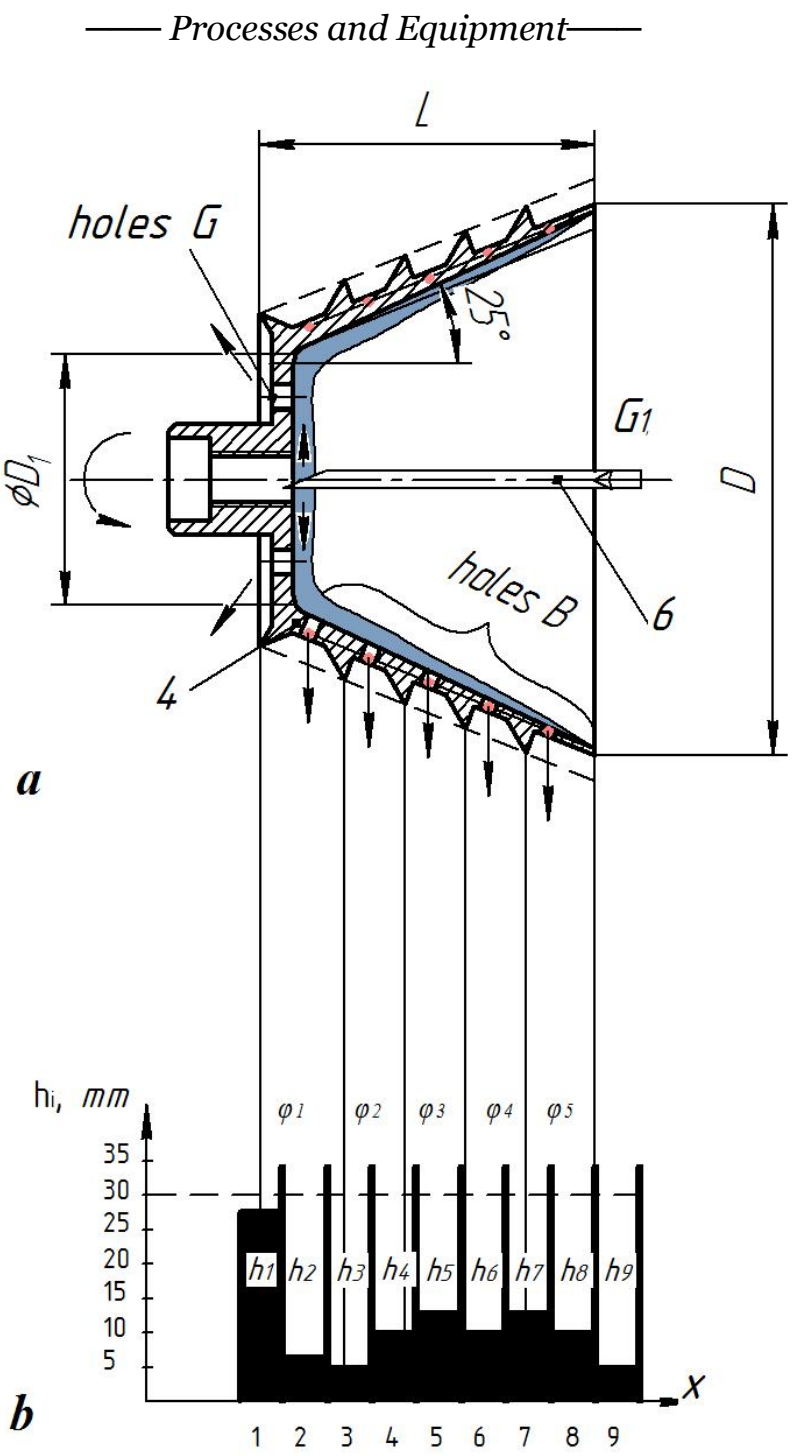

Figure 4. Mechanical disperator type 2:

a - Design of disperator type 2;

b - Flow distribution histogram;

$$
\begin{gathered}
\mathbf{G}=12,44 ; a=0.073 \\
\mathrm{n}=\mathbf{6 0} 1 / \mathrm{s} ; \mathrm{w}=\mathbf{9} \mathrm{m} / \mathrm{s} ; \\
\mathrm{L}=0.47 \mathrm{~mm}
\end{gathered}
$$

On the outer surface, there are setbacks in the interval between the openings with a diameter of 4.5 with the ratio of the coefficients of the living section respectively

$\varphi 1: \varphi 2: \varphi 3: \varphi 4: \varphi 5=1: 1: 3: 5: 5$,

while maintaining the total coefficient of the living section $\mathrm{f}=4 \%$, Figure 4 . Nutrient tube 6 , Figure $4 \mathrm{a}$, small cut edges at an angle of $30^{\circ}$, but turned up. The distance from the internal end surface of the disperator $1_{0}=0$, with similar liquid phase flow rates and the number of revolutions. 
This led to a change in the histogram of mass distribution of the liquid by a disperator, which was determined by the ratio of heights.

Namely

$$
\text { h1: h2: h3: h4: h5: h6: h7: h8 = 5.5: 1.3: 1: 2: 2.6: 2: 2.3: } 1 \text {. }
$$

The analysis of photos of the outer surface of the disperator in the working condition has confirmed the effectiveness of the use of reaming rings. However, in zone 1 there was a significant increase in the parameter $\mathrm{h} 1$, which is due to the approximation of the edge of the power pipe 2 to the end of the disperser, Figure 5a. As a result, through the openings of $\mathrm{G}(6$ pcs. $\varnothing 4,5)$, Figure 5b, there was a large amount of liquid.

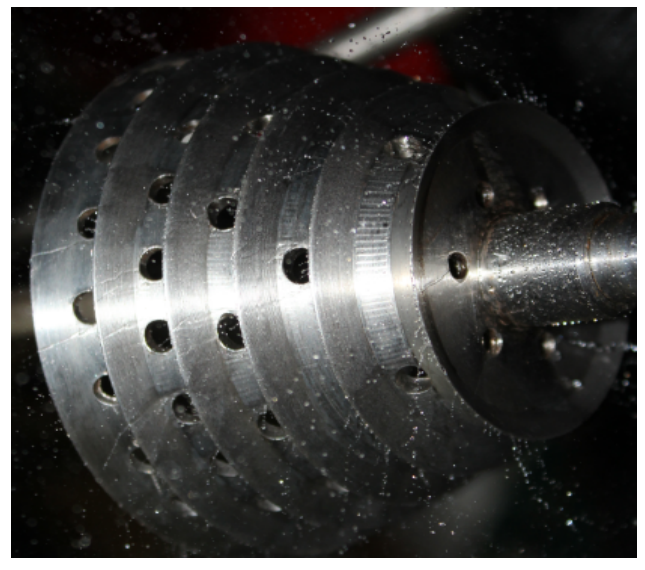

$a$

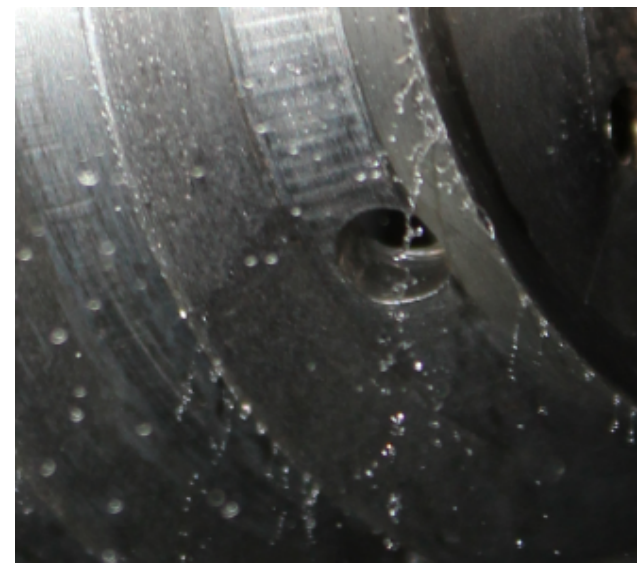

b

Figure 5. Nature of movement on the outer surface of the disperator type 2: a-General view outer surface; b - Liquid flow by outer surface.

In this case, the parameter $\mathrm{a}=0,073 \mathrm{~kg} /(\mathrm{s} \cdot \mathrm{m})$ for both types of disperators was identical. Therefore, the use of bulging rings on the outer surface of a conical di-sphericator has made it possible to significantly improve the distribution mass of the fluid along the length of the disperator 's working area.

To increase the length of the dispersion zone and to improve the uniform distribution of the dispersed liquid, a disperator type 3, Figure 6.

Which represents the mirror image of the disperser type 2 of the introduction of liquid into the central part, Figure 6 . The working solution through the introduction tube 4 is fed into the chamber 3 , in which there is a division into two streams, followed by the formation of a film that moves into a zone of greater diameter, according to the inner surface of the chamber 1, and 1a, Figure 6.

Breakers rings 2 crash the jets of fluid moving on the outer surface of the disperser and promote effective dispersion at a larger length, Figure $7 \mathrm{a}, \mathrm{b}$, working area length $\mathrm{L}=1.63 \mathrm{~L}$. The experiment was carried out with an increase in the mass flow of liquid phase from $\mathrm{G}_{1,2}$ $=12,6$ to $19,6 \mathrm{~kg} / \mathrm{h}$, but with this parameter $a=0,071 \frac{\mathrm{kg}}{\mathrm{s} \cdot \mathrm{m}}$. 


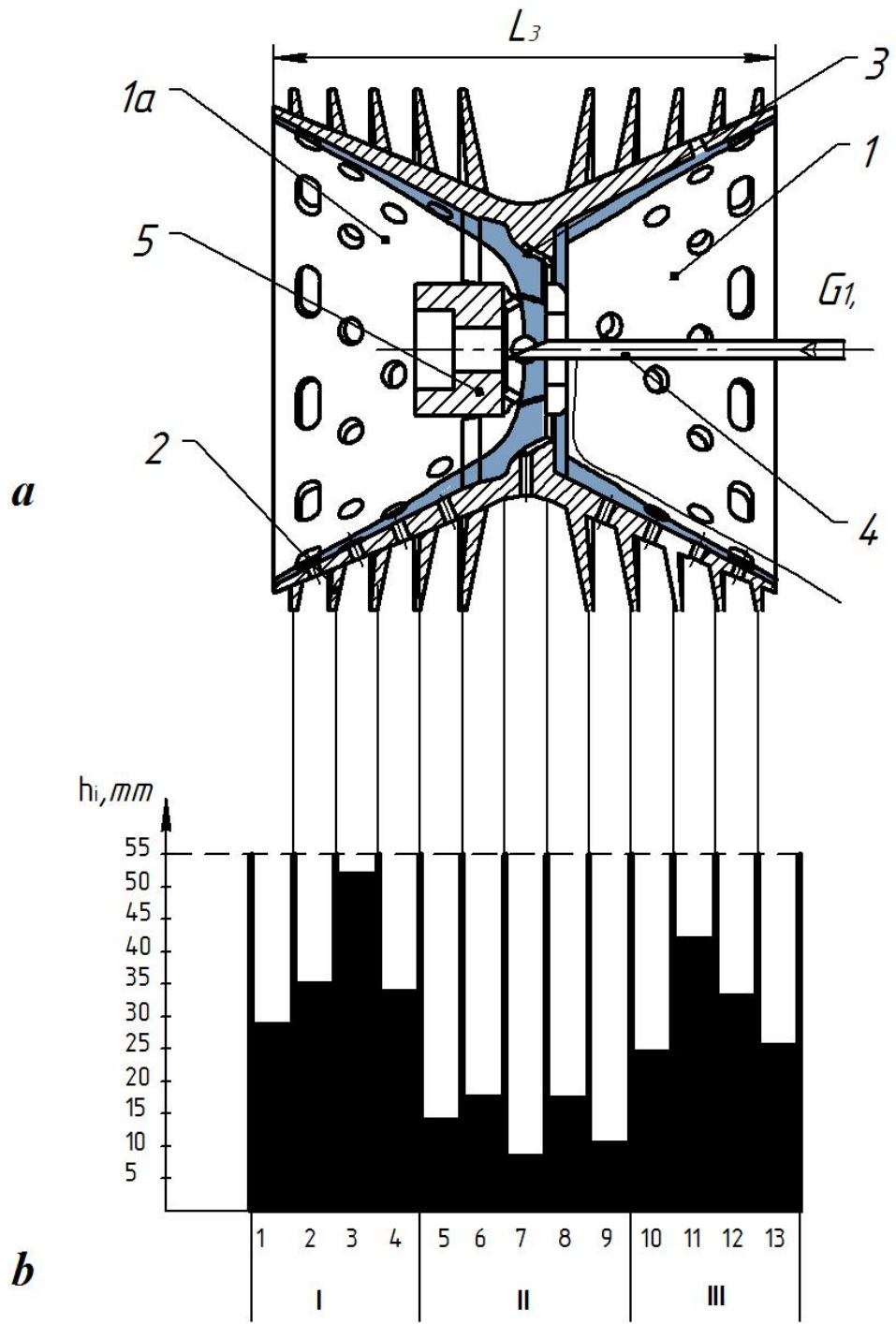

Figure 6. Mechanical disperator type 3:

1 - disperator; 2 - discontinuous rings; 3 - distribution chamber; 4 - tube for giving the working solution; 5 - element of fastening to the shaft;

a - design of type 3 disperators; $L z=1,63, L=77 \mathrm{~mm}$;

$b$ - histogram distribution of fluid along the length $G=19,6, a=0,071 \mathrm{n}=601 / \mathrm{s}=w_{1} 9 \mathrm{~m} / \mathrm{s}$

As a result, it was possible to significantly change the histogram of the distribution along the rotor length

$$
\mathrm{h}_{1}: \mathrm{h}_{2}: \mathrm{h}_{3}: \mathrm{h}_{4}: \mathrm{h}_{5}: \mathrm{h}_{6}: \mathrm{h}_{7}: \mathrm{h}_{8}: \mathrm{h}_{9}: \mathrm{h}_{10}: \mathrm{h}_{11}: \mathrm{h}_{12}: \mathrm{h}_{13}=3,4: 4,2: 6,2: 4: 1,7: 2: 1: 2: 1,2: 2,9: 5: 4: 3 \text {. }
$$

By even distribution, you can conditionally allocate to 3 zones. $h_{I}, h_{\text {III }}$ irrigation zone with disperser 1 and la, with an average value of $h_{I}=37,7 \mathrm{~mm}, h_{I I I}=31,3 \mathrm{~mm}$. In the zone $h_{I I}$, there is an explicit minimum of the hysterograms in comparison with the zones $h_{I}$ and $h_{I I I}$, 
$\mathrm{h}_{\mathrm{II}}=13,64 \mathrm{~mm}$ due to the location of the distribution chamber and reduction of seams in this area $\mathrm{w}_{1}=3-4 \mathrm{~m} / \mathrm{s}$.

The density of the mass distribution of the fluid along the length is determined by the formula:

$$
g_{i}=\frac{h_{i} \cdot G}{\Sigma h_{i} \cdot 3600 \cdot L_{p}}
$$

where $\mathrm{G}$ - mass flow rate of liquid, $\mathrm{kg} / \mathrm{h} ; \mathrm{h}_{\mathrm{i}}$ - height of a column of liquid in a separate cassette cell, mm; $L_{\mathrm{p}}$ - irrigation working area, $\mathrm{mm} ; \sum h_{i}-$ the amount of liquid column heights in all cells, $\mathrm{mm}$.

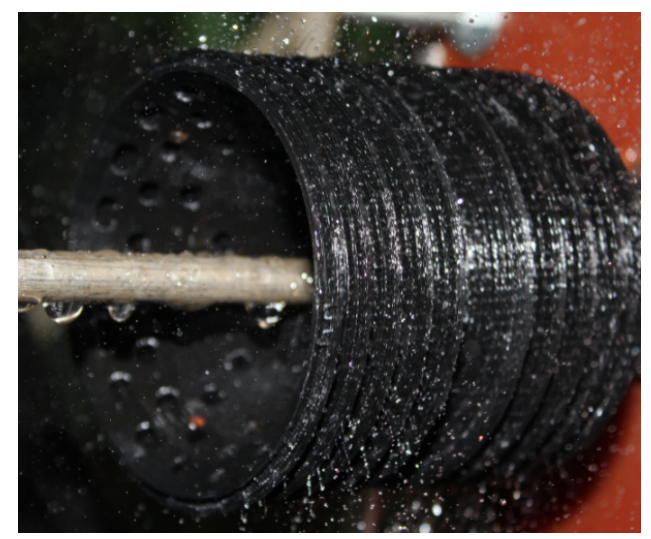

$a$

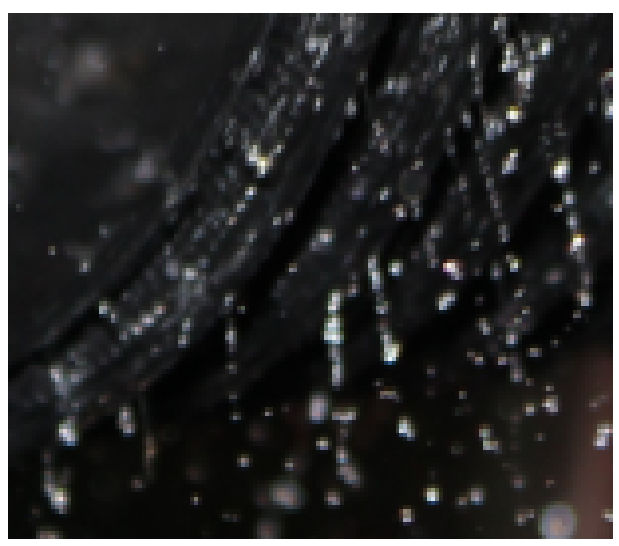

$b$

Figure 7. Nature of movement on the outer surface of the disperator type 3: a-general view of outer surface; b - flow of liquid through outer surface.

The dependence $g=f(L)$ for the three types of disperators is shown in Figure 8 .

The presence of maxima for disperators of type 1 and 2, corresponding to 6 and 3 times the maximum level of the disperator, indicates an unsatisfactory volume distribution of the liquid phase over the working length of the disperator, and therefore the construction of these types of disperators will cause the formation of maximum areas of overflow.

More effective is the disperator type 3 where the ratio is much smaller. 


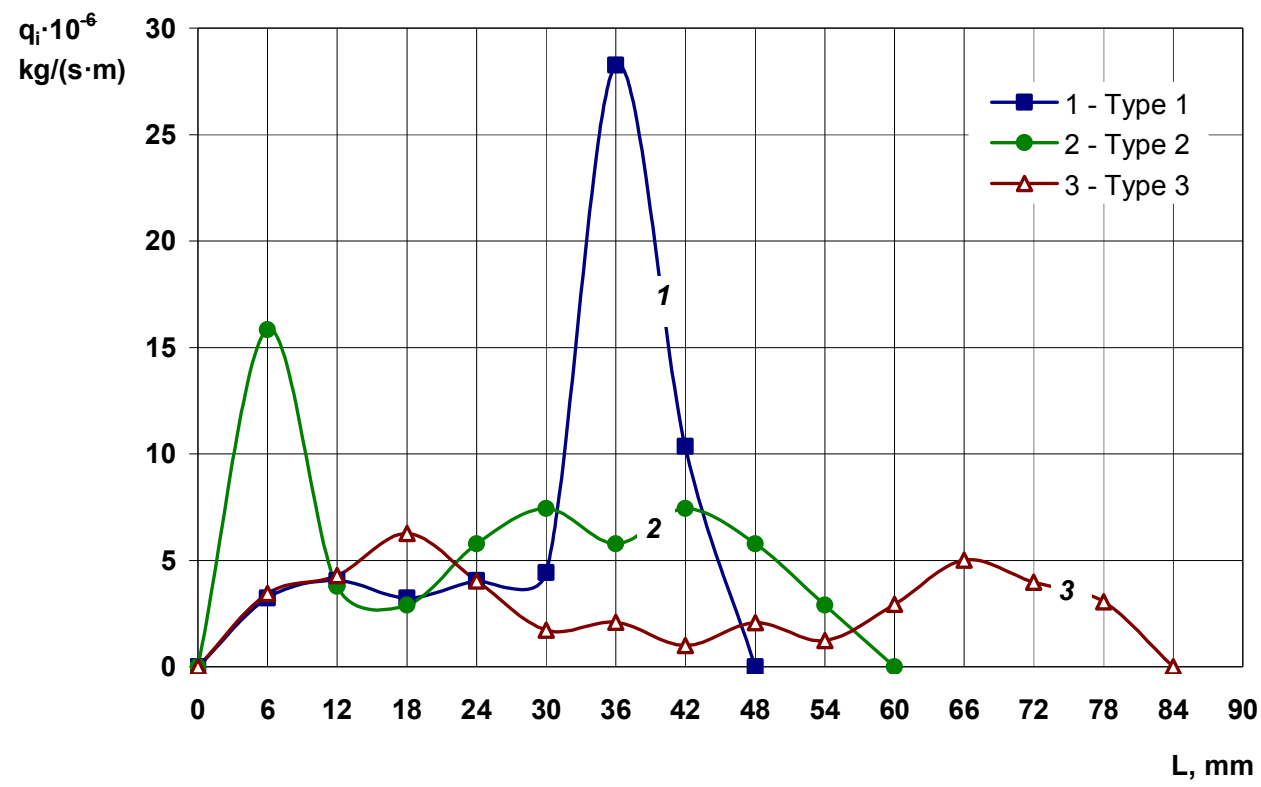

Figure 8. The density of mass distribution of the liquid along the length of the zone disperators for dispersing Type 1, Type 2, Type 3

Quality assessment conducted by the uniformity of dispersion index distribution of mass density fluid dispersion working length:

$$
j_{\max }=\frac{g_{i \max }}{L_{p}}
$$

where $L_{\mathrm{p}}$ - the width of the working spray zone, and $g_{i \max }$ - the maximum value of the density distribution of the fluid in length in a separate measuring flask.

Comparing the results of experimental studies of various types of disperators shows that the minimum value of this criterion is achieved for disperator type 3 , which is 4.5 times less compared with disperator type 1 and 2.5 times disperator type 2, Figure 9.

A very important criterion for the quality of the disperator is the determination of the influence of technological parameters on the size of liquid droplets that arise when working with a disperator. Previous studies have established [12] that the implementation of the layered granule formation mechanism, the average droplet size of the liquid phase should not exceed $10 \%$ of the average grain size. According to the existing quantities to the granular product, the average size of the granules is $D e=2.5 \mathrm{~mm}$, so the average size of drops $\mathrm{d}_{\mathrm{kp}}=0.25 \mathrm{~mm}=250 \mu \mathrm{m}$. 


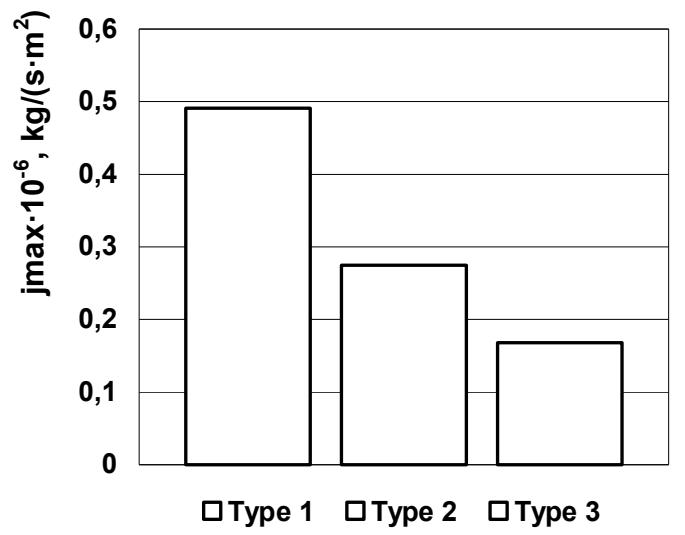

Figure 9. Jmax spray density indexes for different types of disperator

A further study on the size of droplets was performed on type 3 disperator. For the experiment, a fractional factor-type experiment was chosen

$$
n=2^{3-1}
$$

where as parameters were chosen: $x_{1}$ - linear velocity of the edge of the disperser with a maximum internal diameter $\mathrm{D}=47 \mathrm{~mm}$,

$$
x_{1}=\omega \cdot \frac{D}{2}=2 \pi n \frac{D}{2}
$$

where $-\omega-$ number of revolutions of the disperser, $1 / \mathrm{s}$;

$x_{2}$ - flow rate of the liquid phase supplied to the disperator, $\mathrm{kg} / \mathrm{h}$;

$x_{3}$ - the pressure of air supplied to the power supply, MPa.

The limits of measurement of these parameters are given in Table 1.

The value of the main parameters and the limits of their variation

Table 1

\begin{tabular}{|c|c|c|c|c|}
\hline \multirow{2}{*}{ Parameter } & \multirow{2}{*}{ Definition } & \multicolumn{3}{|c|}{ Parameters value } \\
\cline { 3 - 5 } & & Average & Deviation & Dimension \\
\hline $\mathrm{X}_{1}$ & $\mathrm{~W}$ & 15,8 & 4,5 & $\mathrm{M} / \mathrm{s}$ \\
\hline $\mathrm{X}_{2}$ & $\mathrm{G}_{1}$ & 25,75 & 6,2 & $\mathrm{Kg} / \mathrm{h}$ \\
\hline $\mathrm{X}_{3}$ & $\mathrm{As}$ & 0,175 & 0,075 & $\mathrm{Mpa}$ \\
\hline
\end{tabular}

Experiments were carried out on experimental installations with photophixation of droplets of the liquid phase in accordance with the experimental plan Figure 10. 


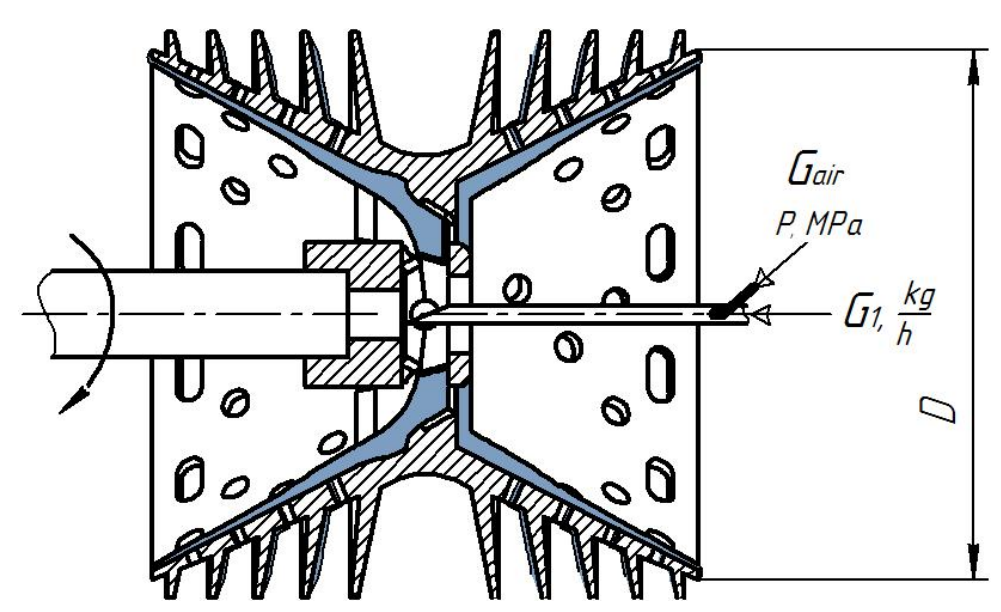

Figure 10. Diagram of determination of droplet parameters

In this case, the parameter a for the range of variation of costs indicated in the experiment plan is applied discretely within: $0,069 \leq a \leq 0,116$

The matrix of planning and experiment results are shown in Table 2

Table 2

The matrix of the plan and the result of the experiment

\begin{tabular}{|c|c|c|c|c|c|c|c|c|c|}
\hline \multirow{2}{*}{ № } & \multicolumn{2}{|c|}{$\mathrm{X}_{1}, \mathrm{~m} / \mathrm{s}$} & \multicolumn{2}{|c|}{$X_{2}, \mathrm{~kg} / \mathrm{h}$} & \multicolumn{2}{|c|}{$\mathrm{X}_{3}, \mathrm{MPa}$} & \multicolumn{2}{|c|}{ D, microns } & \multirow{2}{*}{$\begin{array}{c}\text { Date of } \\
\text { the event }\end{array}$} \\
\hline & Code & Medium & Code & Medium & Code & Medium & Value & Medium & \\
\hline \multirow{3}{*}{1} & + & \multirow{3}{*}{20,3} & - & \multirow{3}{*}{19,6} & - & \multirow{3}{*}{0,1} & 220 & \multirow{3}{*}{221,3} & 12.05 .2017 \\
\hline & + & & - & & - & & 224 & & 12.05 .2017 \\
\hline & + & & - & & - & & 229 & & 12.05 .2017 \\
\hline \multirow{3}{*}{2} & - & \multirow{3}{*}{11,3} & + & \multirow{3}{*}{32} & - & \multirow{3}{*}{0,1} & 410 & \multirow{3}{*}{409} & 14.05 .2017 \\
\hline & - & & + & & - & & 402 & & 14.05 .2017 \\
\hline & - & & + & & - & & 415 & & 14.05 .2017 \\
\hline \multirow{3}{*}{3} & - & \multirow{3}{*}{11,3} & - & \multirow{3}{*}{19,6} & + & \multirow{3}{*}{0,25} & 315 & \multirow{3}{*}{308} & 08.09 .2017 \\
\hline & - & & - & & + & & 308 & & 08.09 .2017 \\
\hline & - & & - & & + & & 302 & & 08.09 .2017 \\
\hline \multirow{3}{*}{4} & - & \multirow{3}{*}{11,3} & + & \multirow{3}{*}{32} & + & \multirow{3}{*}{0,25} & 355 & \multirow{3}{*}{350} & 16.09 .2017 \\
\hline & - & & + & & + & & 347 & & 16.09 .2017 \\
\hline & - & & + & & + & & 349 & & 16.09 .2017 \\
\hline
\end{tabular}



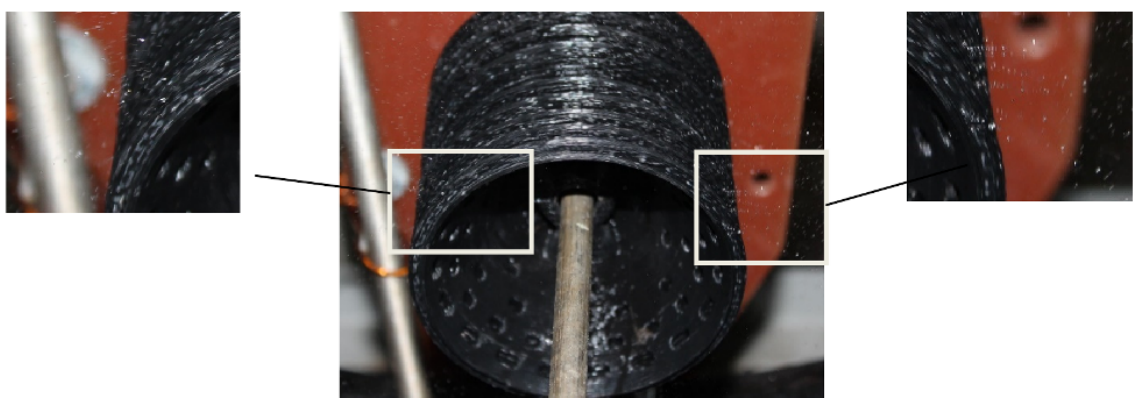

a: $\quad x_{1}=+1,0 ; x_{2}=-1,0 ; x_{3}=-1,0$
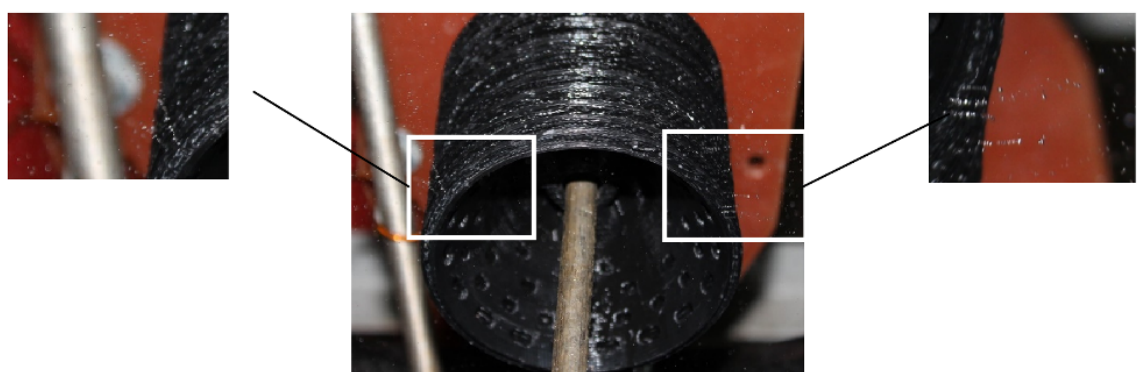

b: $\quad x_{1}=-1,0 ; x_{2}=+1,0 ; x_{3}=-1,0$
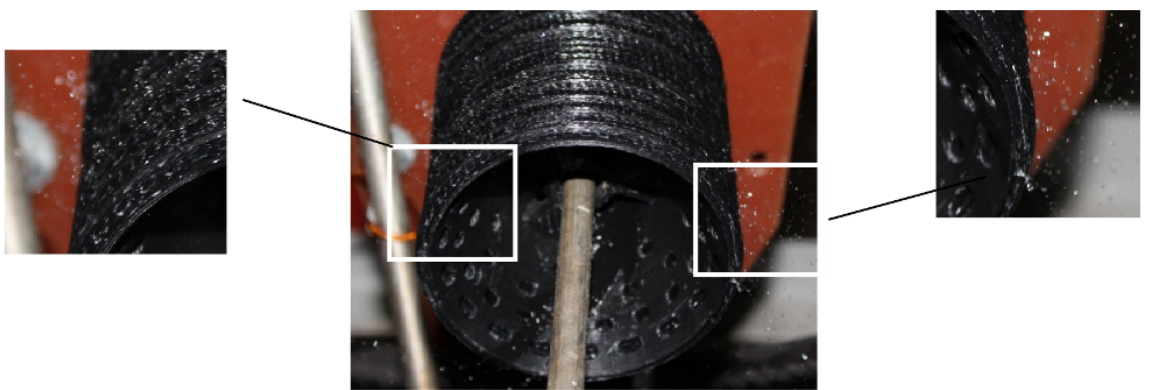

c: $\quad x_{1}=-1,0 ; x_{2}=-1,0 ; x_{3}=+1,0$
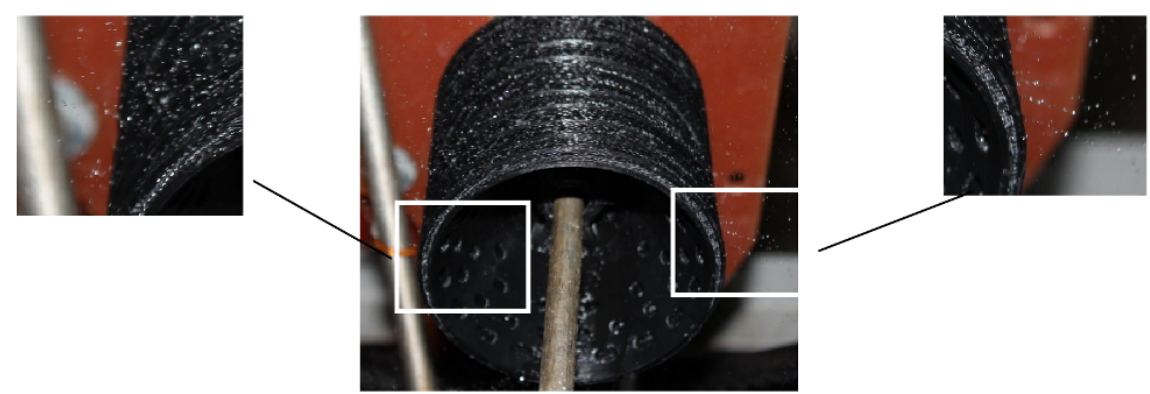

d: $\quad x_{1}=-1.0 ; x_{2}=+1.0 ; x_{3}=+1.0$

Figure 8. Photo fixation of the size of liquid drops when implementing an experiment plan 
Processing the results of the experiment according to the method [13], therefore, in the equation of the form:

$$
\eta=B_{0}+B_{1} x_{1}+B_{2} x_{2}+B_{3} x_{3}
$$

After the transformations of the values of the regression coefficients, we finally get the equation in the normalized coordinates:

$$
\eta=322-36,4 x_{1}+57,4 x_{2}
$$

or in real physical quantities:

$$
\eta=322-9,8\left(x_{1}-11,5\right)+9,2\left(x_{2}-25,7\right)
$$

The analysis of the equations shows that the minimum costs for dehydration dgiv $=250$ microns are predicted at the upper limit of the parameter value $\mathrm{x}_{1}, w_{l}=15 \mathrm{~m} / \mathrm{s}$, and the lower paramiter $\mathrm{x}_{2}=19.6 \mathrm{~kg} / \mathrm{h}$; then it is quite obvious that when increasing the size of the granule, it may be possible to increase the size of the droplets accordingly. But the linear velocity of the edge of the disperator should be at least $w_{p} \geq 9 \mathrm{~m} / \mathrm{s}$. To ensure these requirements, the outer diameter of the shaft rings is practically equal to the internal diameter of the disperser.

\section{Conclusions}

The chosen quality assessment criterion, such as the density index and the size of drops, allows to provide an efficient distribution of the liquid phase. This mechanical disperator is installed inside a fluidized bed which prevents the formation of local overflow zones.

\section{References}

1. Korniyenko Y., Hayday S., Semenenko D., Martynyuk O. (2013), Hranul'ovani azotnokal'tsiyevo-huminovi tverdi kompozyty, modyfikovani bentonitom. Protses oderzhannya, Khimichna promyslovist' Ukrayiny, 5, pp. 46-51.

2. Kornienko Y., Gaidai S., Martyniuk O. (2014), Improved process to obtain granular humic fertilizers, Available at: http://ela.kpi.ua/handle/123456789/11943.

3. Kornienko Y., Gaidai S., Martyniuk O. (2014), Improved process to obtain granular humic fertilizers, Available at: http://ela.kpi.ua/handle/123456789/11943.

4. Ahmed, M., Youssef, M., (2012), Characteristics of mean droplet size produced by spinning disk atomizers, J. Fluids. Eng.-Trans, 134(7), pp. 071103.1-071103.9 (Paper 071103).

5. Ahmed, M., Youssef, M., (2012). Characteristics of mean droplet size produced by spinning disk atomizers. J. Fluids. Eng.-Trans. 134(7), pp. 071103.1-071103.9 (Paper 071103).

6. Ahmed, M., Amighi, A., Ashgriz, N., Tran, H., (2008), Characteristics of liquid sheets formed by splash plate nozzles, Exp. Fluids, 44, pp. 125-136. 
7. Ahmed, M., Ashgriz, N., Tran, H., (2009a), Break-up length and spreading angle of liquid sheets formed by splash plate nozzles, J. Fluids Eng.-Trans, 131(11), pp. 011306.1-11306.9 (Paper 011306).

8. Ahmed, M., Ashgriz, N., Tran, H., (2009b), Influence of breakup regime on the droplet sizes produced by splash-plate nozzles, AIAA J., 47(3), pp. 120-128.

9. Ahmed, M., Abou Al-Sood, M., Ali, A., (2011), A one dimensional model of viscous liquid jets breakup. J. Fluids Eng.-Trans, 133(11), pp. 114501.1-114501.7 (Paper 114501).

10. Ahmed, M. , Youssef, M., Abou Al-Sood, M. (2013), A two dimensional modeling of viscous liquid jets breakup, Acta Mech., 224, pp. 449-512, doi: 10.1007/s00707-0120766-1.

11. Manastyrny M.N., Kornienko Y.N., Lyubek A.N. (2017), The evaluation efficiency of working mechanical liquid distributor, Young Scientist, 11, pp. 6-9

12. Kornienko Y., Haidai S., Liubeka A., Martynyuk O. (2016), Kinetic laws of the process of obtaining complex humic-organic-mineral fertilizers in the fluidized bed granulator, Ukrainian Food Journal, 5(1), pp. 144-154.

13. Krasovskii G.I., Filaretov G.F. (1982), Planning of the experiment, Publishing house of the Belarusian State University, Minsk. 